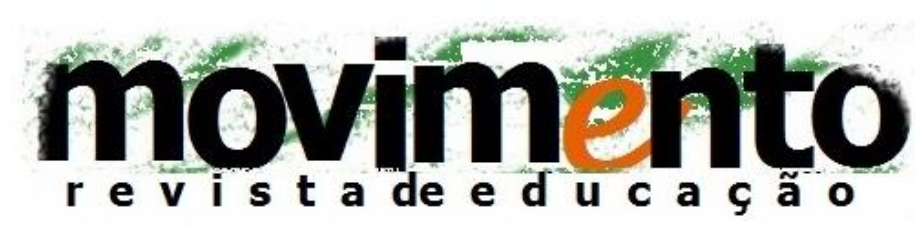

faculdade de educação - programa de pós-graduação em educação

universidade federal fluminense

issn 2359-3296

ano 3 número 5 - 2016

\title{
TRANSFERÊNCIA E EXPERIÊNCIA DOCENTE Psicanálise, educação e sociedade
}

\author{
Maria Angélica Augusto de Mello Pisetta1 \\ Joy Possoni Bejar2
}

\section{RESUMO}

Nestas notas trataremos das atuais condições do laço social e suas repercussões no campo educacional, sobretudo no impacto destas últimas nas relações transferenciais, estabelecidas pelos alunos em direção aos professores. As relações entre o conceito de inconsciente político e transferência estão aqui contempladas na discussão das relações entre as relações entre alunos e professores. Abordaremos as reflexões de psicanalistas e sociólogos no debate em torno das determinações inconscientes presentes no cotidiano das relações escolares entre professores e alunos e procuraremos concluir com uma análise que privilegie 0 ato de professor em seu fazer cotidiano.

Palavras- chave: transferência; psicanálise; educação.

\section{ABSTRACT}

In the text that follows the theme will deal with the current conditions of the social bond and its repercussions in the educational field, especially the impact of these

1 Doutora em Psicologia pela UFRJ, especialista em Psicologia Clínico-institucional pela UERJ, professora adjunta III de Psicologia da Educação da Faculdade de Educação da UFF, pesquisadora vinculada ao Núcleo de Pesquisa Subjetividade, Educação e Cultura NUPES da UFF. E-mail: angelicapisetta@gmail.com.

2 Psicóloga formada pela Universidade Federal Fluminense. Atua principalmente no campo da psicanálise, psicanálise e educação, psicanálise e saúde pública. Atualmente, estuda Fundamentos da Experiência Psicanalítica na área de Saúde Pública na Instituição ESNP/Fiocruz. Atuou como bolsista de iniciação científica em pesquisa e extensão no campo da psicanálise e educação; Atuou como estagiária de psicologia escolar em escolas privadas no Rio de Janeiro; e como estagiária de psicologia clínica em instituição não governamental. Email: 


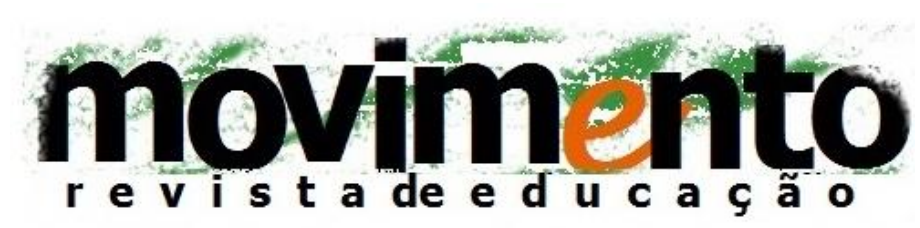

faculdade de educação - programa de pós-graduação em educação

universidade federal fluminense

issn 2359-3296

ano 3 número 5 - 2016

on transference relationships established by students towards teachers. The theoretical relations between the concept of political unconscious and transfer are contemplated herein and are our main objective on the subject of discussion of the relationship between students and teachers. Discuss the reflections of renowned authors on the subject, especially psychoanalysts and sociologists to broaden the debate around the unconscious determinations present in the daily school relations between teachers and students and seek to conclude with an analysis of our reflections that favors the teacher act in his daily tasks.

Key Words: transfer; psychoanalysis ; education.

\section{Psicanálise aplicada}

Concordamos com Furlan (citado por Rosa e Domingues, 2010, p. 180) que consonante com a teoria que lhe dá sustentação, a metodologia se inscreve como "um caminho provisório para entender uma determinada questão". Em se tratando de aplicação de conceitos psicanalíticos ou ainda da extensão de seus conceitos aos fenômenos sociais e políticos, entendemos que tanto a posição do pesquisador quanto os instrumentos idealizados por ele não são dados a priori, mas forjados em seu fazer. A maneira própria de formular as questões, bem como o encontro com sua amostra faz da pesquisa em psicanálise em extensão aos fenômenos sociais um campo de construção permanente de sua teoria e não apenas uma aplicação de conceitos sedimentados historicamente pelo avanço deste campo na clínica do particular. Neste sentido, partimos de uma concepção que pretende superar internamente uma dicotomia entre indivíduo e sociedade, produções singulares e não transmissíveis e produções sociais. Como afirma Rosa e Domingues (2010), entendemos que a pesquisa psicanalítica extensiva aos fenômenos e práticas sociais visa à elucidação da dimensão inconsciente constitutiva e constituída dos mesmos. 


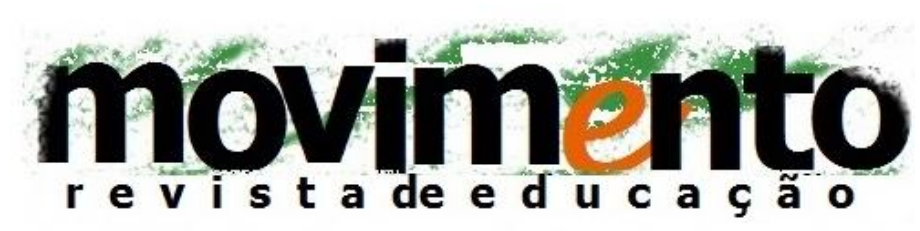

faculdade de educação - programa de pós-graduação em educação

universidade federal fluminense

issn 2359-3296

ano 3 número 5 - 2016

Deste modo, como sublinha Pereira (2012), a entrevista não dirigida e não padronizada própria das investigações dos fenômenos sociais, é acrescida de um viés clínico em psicanálise, na medida em que se debruça sobre as questões pertinentes também ao campo da clínica psicanalítica, como a subjetivação, a análise do discurso que estrutura as relações dos sujeitos envolvidos em determinada dinâmica. Livremente dirigida pelo discurso do entrevistado, a entrevista enviesada pela presença do psicanalista se caracteriza pela não diretividade do pesquisador. O viés clínico que dá consistência à entrevista livremente dirigida promove em sua própria execução um retorno subjetivo para aquele que fala, produzindo, quase sempre, uma reflexão sobre os fenômenos investigados.

Neste sentido, além de sua ênfase clínica, ela ainda resguarda a perspectiva sócio-política, já que auxilia a pensar o que se atualiza no vínculo transferencial entre os alunos e os professores nos dias atuais, revelando os laços sociais contemporâneos. Assim também entendemos que o olhar do psicanalista aos fenômenos sociais e políticos, ainda que não se utilize de entrevistas, requer a mesma disposição, uma aplicação constante dos conceitos fundamentais da psicanálise, de modo a produzir sua metodologia no encontro sempre faltante com seu objeto. Nesse sentido, a amplitude do conceito de transferência como atualização da realidade do inconsciente (Lacan, 1998a), é indispensável, e evidencia os laços entre a psicanálise e a educação.

\section{Subjetividade e docência}

Para estudarmos os impactos da relação professor-aluno na sociedade atual nos interessamos nas identificações das transferências atuais, advindas dos novos 


\section{movimento

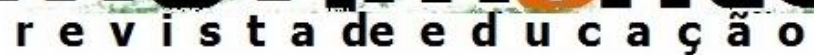

faculdade de educação - programa de pós-graduação em educação

universidade federal fluminense

issn 2359-3296

ano 3 número 5 - 2016

laços sociais. Partimos, inicialmente, da clássica definição freudiana de como se dá o processo transferencial (Freud, 1912/2010).

A transferência está para o sujeito como uma forma de combinação dos fatores inatos somados às experiências dos seus primeiros anos de vida de. Esta combinação influencia na vida erótica desse sujeito, estabelecendo précondições para amar, modos e objetivos de satisfação das pulsões. Assim, essa combinação será impressa em todas as formas deste sujeito se relacionar ao longo de sua existência.

No que diz respeito à clínica, a transferência sustenta o tratamento psicanalítico especialmente a partir de duas atitudes do paciente: de um lado, a cooperação, e de outro, a resistência. Estas atitudes se contrapõem, exibindo cooperação gerada pelo processo de transferência e, por outro lado, hostilidade gerada pela resistência. Essa resistência seria um mecanismo usado pelo indivíduo de impedir que conteúdos inconscientes indesejáveis que estão próximos de serem revelados no consciente, venham à tona e possam tornar-se úteis à realidade. É preciso que o analista seja um intérprete frente às repetições do paciente, tornando estas repetições simbolizáveis. $O$ encontro do paciente com o analista permite uma ressignificação de algo que estava anteriormente recalcado, permitindo uma atualização do mesmo (Freud, 1912/2010).

A teoria da transferência em Freud (1912/2010) conceitua transferência erótica, positiva e negativa. A transferência erótica se dá quando o vínculo transferencial assume um caráter sexual; a transferência positiva refere-se especialmente aos sentimentos idealizados de consideração e admiração e a transferência negativa, quando o vínculo transferencial adquire um caráter hostil. Todas elas comumente estão combinadas na multiplicidade de sentimentos que uma relação comporta. Assim, como aponta Lacan (2003, p. 196): "A transferência, 


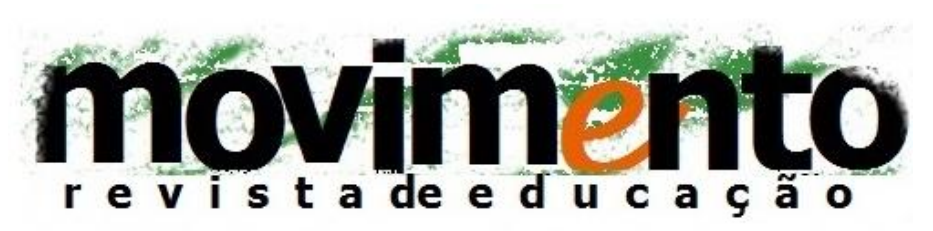

faculdade de educação - programa de pós-graduação em educação

universidade federal fluminense issn 2359-3296

ano 3 número 5 - 2016

como tempo de fechamento ligado à enganação do amor, integrou-se a essa pulsação [do inconsciente]".

Observa-se que no decurso do tratamento psicanalítico começa a ocorrência destes afetos na relação do paciente com seu analista. Todos os sintomas do paciente abandonam seu significado original e assumem um novo sentido que se refere à transferência. $O$ desenvolvimento do que Freud (Idem) nomeou neurose de transferência marca um ponto decisivo na relação analítica de modo que o paciente passa a dirigir seus investimentos libidinais à pessoa do analista. Para Lacan (1992a), a transferência nos possibilita uma releitura das funções e do funcionamento do inconsciente. Não é em condições simplificadas e quaisquer que $\mathrm{o}$ inconsciente se faz elucidar, mas ele pode advir em seus equívocos a partir do encontro com o Outro a quem se fala. Essa é a função da transferência: sustentar a ação da fala e o mesmo tempo ser sustentada pelo ato de falar.

Além do processo de transferência poder ocorrer durante o tratamento analistapaciente, também pode dar-se na relação professor-aluno; como de resto, em qualquer relação que o sujeito venha a manter. Assim, tanto o professor quanto o aluno produzem e sustentam um vinculo afetivo durante o processo de aprendizagem. Este vínculo pode ser tanto positivo quanto negativo, ou ambos, concomitantemente.

Em se tratando dos laços transferenciais dos alunos em direção ao professor, podemos supor um vinculo afetivo "trazido" na transferência positiva quando um aluno é muito próximo do professor, colocando este até mesmo no lugar de um familiar. Já na presença de atitudes hostis (transferência negativa) podemos perceber que há um confronto nesta relação, hostilidade que tem se tornado 


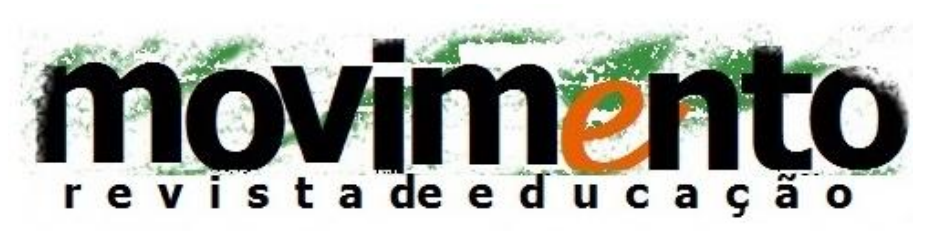

faculdade de educação - programa de pós-graduação em educação

universidade federal fluminense issn 2359-3296

ano 3 número 5 - 2016

cada vez mais comum nos relatos dos docentes. O modo com que enfrentam o real destas relações também está em jogo na queixa que dirigem.

Lacan (1996, p. 104) sublinha que o uso rotineiro e naturalizante das noções fundamentais sobre o homem e sua cultura enfraquecem seu sentido - e aqui sustenta uma crítica à transmissão do que já está estabelecido, que de modo tão repetitivo é ensinado pela escola -. Por outro lado, tais concepções sobre o homem e seu mundo convocam a uma reflexão permanente e atenta, por parte de quem ensina.

Deste modo, a função de quem ensina precisa estar ligada à urgência de resgatar o sentido destas noções, muitas vezes através da construção deste sentido em cooperação com os alunos. Para tanto, é necessária a retomada constante de nossa história particular, de quem nós fomos e ainda de nossa história coletiva, imersa nas imagens de nosso tempo histórico. Aprofundando ainda um pouco, essa retomada requer uma compreensão da produção subjetiva e social subjacente ao trabalho de ensinar. Sendo assim, entendemos que o questionamento sobre as origens do sujeito, como ele se constrói no cotidiano da escola e nas relações estabelecidas ali, precisam estar presente no ato de quem ensina.

Nesse sentido, o valor da experiência deve ser reconhecido na função de quem ensina. Para compreendê-lo precisamos ir além do saber acumulado pelos anos de estudo. Ele diz respeito, sobretudo, ao saber-fazer, um pouco já distante da noção de acúmulo de saber, e também à capacidade de suportar o encargo afetivo da transferência - como dizia Freud (1912/2010), a herança emocional embutido na transmissão. 


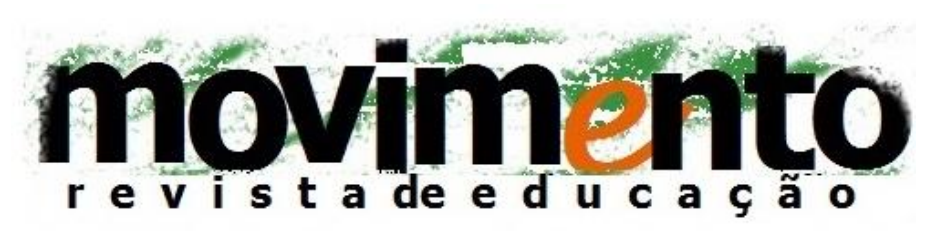

faculdade de educação - programa de pós-graduação em educação

universidade federal fluminense

issn 2359-3296

ano 3 número 5 - 2016

Lacan esclarece que a experiência tem 'alcance de conhecimento e critério de realidade' (1996, p. 105). Nestes termos, reduzir a docência a receitas metodológicas estereotipadas subtrai a subjetividade o reconhecimento do valor da experiência do professor; além de negar a atualidade dos laços sociais atuais com os quais o professor lida em sua prática.

Lacan adverte, também partindo da argumentação da função de ensinar, que podemos tomar a colagem artística como metáfora ou medida do trabalho de quem ensina. A arte da colagem pode ser pensada como metáfora do trabalho do professor, na medida em que neste ato o artista também precisa dar algo seu como matéria prima do objeto produzido, que pode ser seu esforço, sua imaginação, seus movimentos, sua criação, seu desejo, seu ato. Se pensarmos na função de quem ensina, o professor oferece sua própria experiência, seu corpo, sua voz, seu desejo e seu tempo como sua cota na transmissão, que é parte fundante do ato de ensinar.

Por princípio, segundo o autor, essa cota de desejo oferecida e perdida na transmissão é própria da dinâmica da linguagem, que em si exige sempre renúncia do ser falante. Para falarmos perdemos sempre algo no ato de dizer, na busca permanente de nos fazermos entender e na constante experimentação de um certo grau de impossibilidade de tudo explicar. Deste modo, a linguagem provoca evocação mais do que informação (Lacan, 1996, p. 301). Para informarmos, produzimos a evocação e o sujeito que escuta, quando ouve, é convocado a evocar, para construir algum sentido a partir do que ouviu.

Lacan (1996) acentua que se privilegiamos a informação no discurso, mais se experimentamos a redundância, sublinhando que há ressonâncias próprias do discurso que não se deixam neutralizar pela busca de objetividade da 


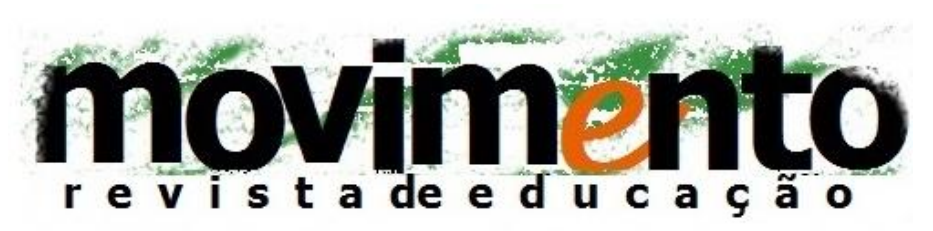

faculdade de educação - programa de pós-graduação em educação

universidade federal fluminense issn 2359-3296

ano 3 número 5 - 2016

informação. Não podemos, no entanto, deixar de considerar o atravessamento da instituição escolar no estabelecimento da transferência, o que discutiremos brevemente agora.

\section{Transferência e instituição}

Podemos pensar ainda como o processo institucional das escolas, e de modo mais abrangente, as condições políticas e sociais da escola interferem nestas relações transferenciais, à medida que estabelecem o enquadre ou o discurso (Lacan, 1992b) que situa os sujeitos em determinada relação. Um exemplo disto é a disciplinarização que as instituições escolares impõem aos seus alunos. Buscamos em Vigiar e Punir (1987) de Michel Foucault, um aparato para discutir sobre o processo disciplinar que os corpos sofrem na medida em que tentam se enquadrar em determinada instituição e momento cronológico e social.

No século XVII durante a época clássica, o corpo passou a ser visto como algo possível de se modelar. Em épocas anteriores, o corpo já havia sido colocado como objeto, mas, o que Foucault traz é que agora outra questão se une ao corpo: o poder. O cálculo dos elementos, a manipulação dos gestos e os estudos dos comportamentos contribuem para a disciplina do corpo. O exercício do poder impõe o controle e disciplina dos corpos dos outros utilizando determinadas técnicas disciplinares. Assim, estes corpos através da disciplina estariam cada vez mais aptos a serem corpos produtivos e obedientes. Foucault cita como um exemplo de corpos disciplinados e fabricado os soldados da época.

Os métodos disciplinares tornaram-se fórmulas de dominação; assim, quanto mais obediente o corpo, mais útil. Para Foucault (1987), a disciplina é vista como 


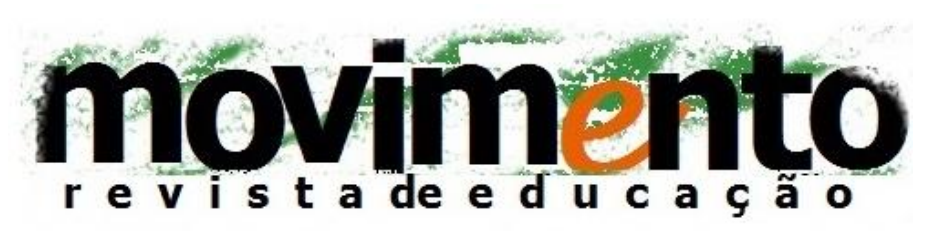

faculdade de educação - programa de pós-graduação em educação

universidade federal fluminense

issn 2359-3296

ano 3 número 5 - 2016

uma anatomia política do detalhe, onde tudo deve ser minuciosamente inspecionado, controlado e os regulamentos devem ser seguidos corretamente.

Frente às questões disciplinares expostas por Foucault, podemos discutir sobre esta maneira de disciplinar corpos dentro de uma instituição escolar de nosso tempo, já modificada em muito em relação aos valores sociais tão bem identificados por Foucault. A liberdade e busca de autonomia como imperativos sociais atuais (Enrenberg, 2004) precisa ser pensada como condicionante inconsciente que propõe novas formas de laço social e novas transferências.

Atualmente, a imagem do professor difere daquela imagem prestigiada construída nos séculos XIX e XX. Vários pesquisadores referem a ocorrência de um declínio do "discurso do mestre" - um dos discursos introduzidos por Lacan (1992b); ao lado do discurso universitário, do discurso da histérica e do discurso do analista; para identificar as formas como as pessoas se relacionam. Embora não possamos fazer uma equivalência entre o discurso do mestre - conforme proposto por Lacan - e as relações, tanto conscientes quanto inconscientes, que os professores propõem, há ressonâncias e entrecruzamentos no que diz respeito à prática profissional do professor e a mestria como discurso.

O mestre seria um agente que detém o poder e que para exercê-lo precisa do trabalho do escravo ou servo, exercendo sua autoridade, a partir do semblante de poder: "O mestre é fálico, ainda também que seja um castrado. Sujeita-se à lei, mas precisa induzir à sujeição, para conferir ao seu aluno sua autoridade" (Pereira, 2012, p. 43).

Vale ressaltar que para pensar nas relações entre 0 aluno e o professor atualmente, é importante salientar algumas condições atuais do exercício da 


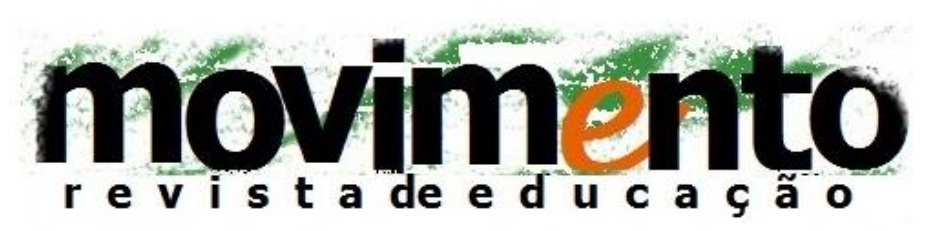

faculdade de educação - programa de pós-graduação em educação

universidade federal fluminense issn 2359-3296

ano 3 número 5 - 2016

docência: as condições precárias de trabalho, a burocracia escolar, a falta de tempo para estudar e se dedicar às diferenças que compõem o alunado, 0 choque gerencial, as relações difíceis com os alunos e o desprestígio da profissão; bem como as questões da subjetividade do docente. Essas condições discursivas fazem o professor se questionar sobre o papel que ele ocupa nessa nova estrutura social, questionando se ainda tem alguma autoridade perante sua classe. Do mesmo modo, pode ocorrer uma sobrecarga emocional que pode gerar estresse, tristeza, raiva, sensação de fracasso e desmotivação (Esteve, 1999).

Dentro deste contexto, o aprofundamento do discurso como conceito fundamental (Lacan, 1992b) referente às formas de relação presentes no laço social pode ser caminho para a abordagem deste intricado problema, queixa corrente dos docentes em relação ao seu trabalho. Todo discurso estabelece os modos de relação de um sujeito com o outro, sendo uma estrutura que permeia todo o laço social.

A importância de considerar o discurso gerado pelos professores se sustenta na expectativa de que toda vez que falamos estamos posicionados em determinado lugar e assim, estamos também colocando o outro em determinada posição. Ouvindo o professor falar pode-se analisar o laço social em que ele está inserido e a partir da conscientização de sua fala poder haver uma reflexão acerca de seu discurso. Nestes termos, questões sobre o que acontece na escola, bem como a troca de experiências, a interlocução entre os pares, trazidas pelos próprios docentes, podem possibilitar que os professores se interroguem sobre suas ações e sobre o mal-estar gerado no campo educacional.

\section{Referências}




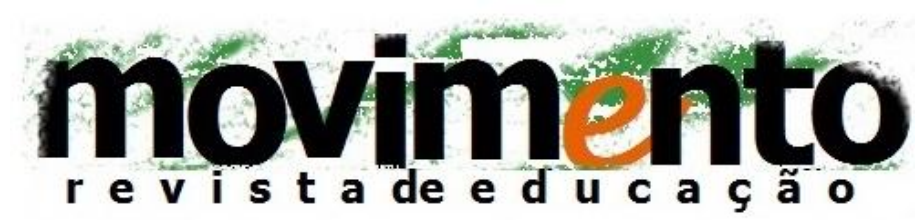

faculdade de educação - programa de pós-graduação em educação

universidade federal fluminense issn 2359-3296

ano 3 número 5 - 2016

ESTEVE, J.M. O mal-estar docente: a sala de aula e a saúde dos professores. Bauru: EDUSC, 1999.

FREUD, S. A dinâmica da transferência. Em: Sigmund Freud, Obras completas, volume 10, pp. 133-146. São Paulo: Editora Companhia das letras, 2010. (Trabalho original publicado em 1912).

FOUCAULT, M. Vigiar e punir. Petrópolis: Ed. Vozes, 2009.

LACAN, J. O seminário, livro 8: A transferência. Rio de Janeiro: Jorge Zahar, 1992a.

LACAN, J. O seminário. Livro 17. O avesso da psicanálise. Rio de Janeiro: Jorge Zahar editora, 1992b.

LACAN, J. Função de campo da fala e da linguagem em Psicanálise. Em Escritos. (pp. 238-324) São Paulo: Editora Perspectiva, 4å . Edição, 1996.

LACAN, J. Intervenção sobre a transferência. Em Escritos. (pp. 214-228) São Paulo: Editora Perspectiva, 4⿳亠丷. Edição, 1998.

LACAN, J. Os quatro conceitos fundamentais da psicanálise. Em Outros escritos. (pp. 195-198). Rio de Janeiro: Jorge Zahar, 2003.

PEREIRA, M.R. Acabou a autoridade? Professor, subjetividade e sintoma. Coleção EDVCERE. Belo Horizonte: Fino traço editora, 2011.

ROSA, M.D. e Domingues, E. O método na pesquisa psicanalítica de fenômenos sociais e políticos: a utilização da entrevista e da observação. Psicologia \& Sociedade, 22 (1) 180-188, 2010.

THIOLLENT, M. Notas para o debate sobre pesquisa-ação. Em C. R. Brandão. Repensando a pesquisa participante. (pp. 82-103). São Paulo: Brasiliense, 1997. 